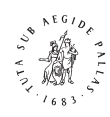

B R I L L

\title{
Verb-Initial versus Subject-Initial Clauses in Greek: Eventuality Existentials versus Predication Clauses*
}

\author{
Yoryia Agouraki \\ University of Cyprus \\ gpyoryia@ucy.ac.cy
}

\begin{abstract}
The paper aims to describe (a) the distribution, (b) the semantic interpretation and (c) the semantic and syntactic derivation of verb-initial versus subject-initial clauses in Greek. Concerning (a), it is argued that the verb-initial and the subject-initial word orders are in complementary distribution. A particular numeration can be assembled in only one way, i.e. as a verb-initial or as a subject-initial word order. The properties of the numeration that play a role in determining the word order for that numeration include the syntactic type of the predicate, the presence or not of non-arguments, the presence or not of sentential operators, and the mode of presenting information. Concerning (b), it is proposed that the semantic interpretation of verb-initial versus subjectinitial clauses can be described as a clause-type distinction between eventuality existentials versus predication clauses. Concerning (c), it is proposed that this clause-type distinction has to do with how the subject and the predicate are put together semantically/syntactically. Namely, it is proposed that in eventuality existentials (the entity denoted by) the subject saturates/is selected by (the property denoted by) the predicate, while in predication clauses it is (the property denoted by) the predicate that saturates/is 'selected' by (the second-order property denoted by) the subject. For the proposed analysis to be right, (a) the clause-type distinction between eventuality existentials and predication clauses, (b) the complementary distribution of the two clause types and (c) the semantic/syntactic derivation for the two clause types must be part of UG. What cannot be part of UG is the syntactic manifestation of this semantic distinction across languages.
\end{abstract}

\footnotetext{
"The research reported here is part of a larger research project on clause type information. I am grateful to the two reviewers for reading a condensed, not always clear text, and pointing out, in their detailed comments, a number of obscure statements and inadequacies, thus helping me to focus on a more balanced presentation of the analysis. A first version of the analysis was presented at a University of Cyprus talk in September 2010 (Agouraki 2010b). I would like to thank the members of that audience, and in particular Despina Chila-Markopoulou, Kleanthes K. Grohmann, Angela Ralli and Ian Roberts, for their insightful observations, which triggered a number of thoughts. Last, I would like to thank Brian Joseph for his comments on the form of the paper, and Michalis Georgiafentis for his innate kindness. The majority of Greek examples come from two novels, Lena Divani's (2010) A Hungry Mouth, and Ioanna Karystiani's (2006) Swell.
} 
Keywords

verb-initial clause; subject-initial clause; eventuality existential clause; predication; unaccusatives; sentential operators; dynamic information; static information

\section{Introduction}

The paper discusses the distinction between verb-initial and subject-initial clauses in Greek. Standard assumptions in Greek linguistics about word order variation are summed up in Georgiafentis (2004:172) as follows:

Greek exhibits great flexibility with respect to word order. A system of rich nominal inflection allows syntactic relations among clausal elements to be identified without being placed in fixed positions. Thus, for example, a simple declarative clause consisting of a verb and its nominal subject and object can be rendered with all six possible combinations, namely SVO, VSO, VOS, OVS, OSV and SOV. However, these configurational possibilities are neither equally common nor pragmatically equivalent. The same holds with respect to their ... intonational properties. Thus, only SVO, VSO and VOS are available in neutral intonation. With respect to the dominant or basic order, Greek has been traditionally classified as an SVO language. However, within the generative framework the status of SVO as being the basic word order in Greek has been questioned. ... Philippaki-Warburton has pointed out that the basic word order should be the least marked order syntactically, intonationally and pragmatically (cf. Philippaki-Warburton 1982, 1985, 1989, 2001). Philippaki-Warburton argues that these criteria are best fulfilled by VSO. Also Tsimpli (1990) has taken SVO to be a derived order, the result of subject Topicalization.

In addition, there is the standard assumption that all types of predicates (transitives, unaccusatives, unergatives) can occur in both word orders, hence in the verb-initial word order (cf. Alexiadou and Anagnostopoulou 1998 and Kechagias 2011). A different description of word-order facts in Greek is provided in Sasse (1987:537), who argues that "In Modern Greek the rule [i.e. the rule that verb-initial sentences are mostly encountered with intransitive verbs or with transitive verbs having pronominal objects, while full noun objects occur quite rarely in the verb-initial order] is not so strict, but in any case VS order is less frequently found in sentences having full objects". Irrespective of whether Sasse's description, on the basis of sentences included in texts, is totally accurate, the description marks a different approach to word order data, and, arguably, is very important for three reasons. (a) Methodologically, it tells us that a description should be based on data found in texts, not isolated sentences. (b) Contentwise, this is the only proposal I know of that some distinction having to do with properties of the predicate (i.e. the intransitive-transitive distinction in Sasse's proposal) is taken to determine, to some extent at least, word order. And (c) in terms of the syntax-semantics interface, the verb-initial/subject-initial distinction is tied to a semantic distinction that concerns the overall meaning of the respective sentences, i.e. Kuroda's distinction between thetic and categorical sentences. However, the link between the syntactic distinction and the 
semantic distinction is not accounted for. This type of proposal should be contrasted with the Topicalization analysis of subject-initial clauses. What is perceived as an interpretation of the subject in the Topicalization theory is perceived as a particular interpretation for the overall sentence in Sasse's/Kuroda's theory. The shift from 'seeing' subject-initial sentences as involving topicalized subjects to 'seeing' them as having an overall interpretation of their own, that does not involve a particular/distinct interpretation for the subject as such, is, in my view, extremely important. In this paragraph I have described the frame for the discussion of word order facts in this paper. The discussion on the two approaches to word order facts is continued in Section 3 .

The paper has two aims, i.e. a language-specific aim and a cross-linguistic aim. The language-specific aim is twofold, namely to describe (a) the distribution and (b) the semantic interpretation of verb-initial and subject-initial clauses in Greek. Concerning (a), it is argued that the verb-initial and the subject-initial word orders are in complementary distribution. A particular numeration can be assembled in only one way, i.e. as a verb-initial word order or as a subject-initial word order. The properties of the numeration that are shown to play a role in determining the word order for that numeration include the syntactic type of the predicate (i.e. unaccusatives vs. all other predicates), the presence or not of non-arguments (in sentences with unaccusatives), the presence or not of sentential operators (in sentences with agentive/intentional predicates), and the static mode of presenting information (in sentences with all predicate types). Concerning (b), it is proposed that the semantic interpretation of verb-initial versus subject-initial clauses can be described as a clause type distinction between eventuality existentials versus predication clauses. It is shown that the second claim is not unrelated to the first one.

The cross-linguistic aim of the paper is again twofold, namely (a) to explore whether the proposed clause type distinction between eventuality existentials and predication clauses is a universal semantic distinction, with distinct syntactic manifestations across languages, and (b) to propose a semantic and a syntactic derivation for the two clause types. If this clause type distinction is part of UG, the proposed derivations should be of a general form, so as to capture the distinct syntactic manifestations of this distinction across languages. It is argued that this is a universal distinction and that the two clause types differ in how the subject and the predicate phrase are put together semantically/syntactically. Namely, that in eventuality existentials (the entity denoted by) the subject saturates/is s-selected by (the property denoted by) the predicate, while in predication clauses it is (the property denoted by) the predicate that saturates/is c-selected by (the second-order property denoted by) the subject.

The paper is divided as follows. Section 2 accounts for the order in which different types of data will be examined. Section 3 examines the distribution 
pattern of verb-initial and subject-initial matrix affirmative clauses with neutral stress. It is shown that they are in complementary distribution. In sentences with arguments only, the word order is VS for unaccusative predicates, and SV for all other predicates. In sentences with non-arguments, SV is the only possible word order, irrespective of predicate type. In Section 4 it is claimed that the semantic interpretation of verb-initial versus subject-initial clauses can be described in terms of a clause-type distinction between eventuality existentials versus predication clauses. Although predication clauses are standardly taken to 'target' the subject, it is argued that they can, alternatively, 'target' the direct or the indirect object. The proposal for a semantic distinction between two clause types builds on Kuroda's $(1972,1992)$ distinction between thetic and categorical judgments. A proposal for the semantic derivation of eventuality existentials and predication clauses is put forward. It is shown next that, apart from unaccusatives without non-arguments, which obligatorily yield the VS order, there are two more 'mechanisms' that optionally yield the VS order, i.e. sentential operators and the static mode of presenting information. The two mechanisms are discussed in Sections 5 and 6 , respectively. Section 7 examines whether the distinction between eventuality existentials and predication clauses is part of Universal Grammar. The syntactic manifestations of this distinction in English are briefly discussed. Section 8 explores the syntactic derivation for eventuality existentials and predication clauses.

\section{The Logic behind the Selection/Taxonomy of the Data}

Looking at Greek word order data and reading about Greek word order, I have come to two methodological conclusions. (a) Word order is a phenomenon that can be adequately studied at text level. We should only be looking at sentences within a text, rather than constructed and/or isolated sentences. If native speakers construct examples, these should be inserted in small texts. Only if particular examples are considered acceptable within a text should they be included in the data under examination. Differences in acceptability judgments among native speakers most probably have an explanation relating to data quality control in terms of whether the data pass the insertion in text test. It would be surprising if there were corresponding differences in the linguistic performance of native speakers. Looking at examples within a text is different from putting examples in a context. And (b) it could make a difference with respect to word order whether a particular sentence is part of a sequence of events or not. If a sentence is not part of a sequence of events, then the speaker zooms in on a particular point in time/ time interval and describes the state-of-affairs at that point in time/ time interval. The distinction between having a sequence of 
events or not is phrased as a distinction between a dynamic and a static mode of presenting information.

The puzzle I address in this paper, with respect to word orders with neutral intonation, is the description that the various word orders "are neither equally common nor pragmatically equivalent". It is argued that the notions relating to frequency of occurrence, pragmatics and context reduce to syntactic factors, i.e. the distinction between a dynamic and a static mode of presenting information and the absence versus presence of non-arguments, and that these syntactic notions, which will be used to divide up the data, is all we need to make sense of the data. Breaking up the data like that is part of the working hypothesis investigated and defended. The taxonomy of the data first takes into account the distinction between presence versus absence of a sequence of events. In Section 3 I look at data which are taken to form part of a sequence of events. More specifically, in Sections 3.1-3.2 I look at matrix affirmative sentences with neutral, i.e. clause-final, stress and arguments only. In Section 3.3 I examine matrix affirmative sentences with neutral stress and non-arguments. In Sections 5 and 6 I look at data which do not form part of a sequence of events. These data could include clauses with sentential operators (cf. Section 5), be they 'actual world' operators or possible worlds operators, or not (cf. Section 6). Some sentences in Section 3 can occur either in a sequence of events or not. It is claimed that their word order properties are partly different, depending on whether they occur in a sequence of events or not.

\section{The Complementary Distribution Pattern of Verb-Initial and Subject- Initial Clauses}

The standard assumption about word order variation in Greek is that the verbinitial order is the least marked order syntactically and pragmatically, and that the subject-initial order is a derived order, the result of subject Topicalization. It is possible to advance five arguments against deriving the subject-initial order from the verb-initial order through subject Topicalization. First, if we adopt the standard assumption, the prediction is that every numeration can be constructed as a verb-initial or a subject-initial order, depending on the linguistic and situational context. ${ }^{1}$ As shown in Sections 3.1-3.3, the prediction is not confirmed. Second, according to the standard assumption, which one of the two word orders obtains has to do with an interpretable feature on the subject, i.e. [Topic]. Crucially, it has nothing to do with aspects of clause structure in the

\footnotetext{
1) Obviously, for the subject-initial order, the numeration will need to include a Topic head and a Topic feature on the subject.
} 
lexical layer, the inflectional layer or the complementizer layer. As shown in Sections 3.1, 3.2, 5 and 6, this prediction is not confirmed, either. Third, the Topicalization analysis involves the misleading assumption that verb-initial clauses are less marked in a way, while it is only the case that they have a different distribution than subject-initial clauses (cf. Sections 3.1-3.2). Fourth, the concept of Topicalization does not distinguish between subject (or arguments) and nonarguments. Thus, the interpretation of the subject-initial word order is not set apart from the interpretation of a sentence with a topicalized non-argument. Still, there can be shown to exist interpretational differences between sentences with preverbal arguments and sentences with preverbal non-arguments. Finally, in the Topicalization approach the difference in interpretation between the subject-initial order and the verb-initial order is confined to the interpretation of the subject and, allegedly, relates to an interpretable feature on the subject. Verb-initial and subject-initial sentences are taken to involve the same relationship between the predicate and the subject, i.e. predication. In fact, the term predication is used to refer to just that, i.e. the grammatical relationship between a predicate and a subject. Predication brings about the saturation of a property. There are three facts this approach does not seem to be able to account for. Namely, (a) the fact that in the subject-initial order the sentence is about the so-called topic. (b) The fact that Greek sentences with so-called topicalized subjects are interpretively equivalent to English subject-initial sentences with clause-final stress, which, crucially, are not taken to involve Topicalization. (c) The fact that it is possible to topicalize indefinite, quantificational (cf. ( $1 \mathrm{~b})$ and $(2 \mathrm{~b})$ in Section 3.1) or definite subjects when they are first introduced in discourse. It is argued in Sections 4 and 8 that the two word orders involve a different relationship between the predicate and the subject, i.e. absence of attribution of a property in the VS order versus attribution of a property in the SV order. This is a philosophical notion of predication, i.e. predicating a property of an individual, which should be contrasted with the syntactic notion of predication. In the standard approach, the syntactic notion of predication is assumed to obtain in both word orders, and the difference in interpretation between the two orders relates to an interpretable feature on the subject. In the theory I will be proposing, the subject DP is interpreted identically in the two word orders. The difference in interpretation between the two word orders is taken to involve a different relationship between the subject and the rest of the sentence in the two word orders, i.e. predicating, or not, a property of an individual.

The first aim of the paper, which relates to the first two arguments against deriving the subject-initial order from the verb-initial order through subject Topicalization, is to illustrate the complementary distribution between the verb-initial word order and the subject-initial word order, in the sense that 
it is possible to predict, on the basis of properties of the numeration, which numeration is assembled into which word order. And this has nothing to do with the linguistic or situational context. It is mainly information in the lexical layer (cf. Sections 3.1-3.3) and, to a lesser extent, information contained in the inflectional layer or the complementizer layer (cf. Sections 5 and 6 ) that determine word order. Sections 3.1-3.2 examine the distribution of verb-initial and subject-initial clauses in matrix affirmative sentences with neutral, i.e. clausefinal, stress and arguments only. Matrix affirmative sentences are chosen so that information contained in the complementizer layer or the inflectional layer does not possibly play a role. Also, where possible, sentences are taken to form part of a sequence of events narration. It is argued that the distinction between verb-initial and subject-initial clauses correlates with unaccusativity. In particular, that the verb-initial word order is only possible with unaccusative predicates, while the subject-initial word order obtains with all other predicates. If, however, a numeration with an unaccusative predicate contains a nonargument, the numeration has to be assembled as a subject-initial word order (cf. Section 3.3).

\subsection{Nonexistence of Ideal Minimal Pairs}

As stated, the first aim of the paper is to describe the distribution of verb-initial and subject-initial clauses. I will start the discussion with the 'ideal' minimal pairs in (1a-b) and (2a-b), which, prima facie at least, seem to suggest that the two word orders are in free distribution for the same numeration. For reasons that will soon become apparent, translations for the pairs of examples in (1) and (2) are not provided at this stage.
(1) a. eminan pede stratiotes sto stratopeðo remained-3PL five soldiers-NOM in the camp-ACC
b. pede stratiotes eminan sto stratopeðo five soldiers-NOM remained-3PL in the camp-ACC
(2) a. akolu $\theta$ use ena taksi followed-3SG a taxi-NOM
b. ena taksi akolu $\theta$ use a taxi-NOM followed-3SG

Examples ( $1 \mathrm{~b})$ and $(2 \mathrm{a}-\mathrm{b})$ are uttered with sentence-final stress, while in example (1a) neutral sentence stress falls on the postverbal subject, and not on the sentence-final content word stratopeðo, as in $(1 \mathrm{~b})$. This difference is accounted for in footnote 4 .

The pairs of examples in (1) and (2) appear to be ideal minimal pairs, in the sense that they consist of the same numeration and differ only in word order. 
They are interesting for two reasons, which have to do with the general description that "word order variants are neither equally common nor pragmatically equivalent". The first reason is because the members of these ideal minimal pairs appear to be equally 'common', in the specific sense this word is used to mean equally 'acceptable'. The second reason is because the members of each pair seem to have a semantic difference, not a pragmatic one, that is easily described. In particular, in the first pair of examples one reading simply states what happened, i.e. that there used to be more soldiers in the camp and there are only five now (cf. (1a)), while the other reading involves an active decision on the part of the soldiers to stay (cf. (1b)). In the second pair of examples one reading is that there was a taxi behind us (cf. (2a)), while the other reading is that a taxi was driven behind some other car, probably with the intention of going wherever the other car went $(\mathrm{cf} .(2 \mathrm{~b})) .^{2}$ The distinction between the readings in each pair is in terms of agenthood. And it is not possible to have the first interpretation with the second sentence in each pair. Nor is it possible to have the second interpretation with the first sentence in each pair. At this point, I should reveal that the very accurate descriptions of the meaning differences in examples (1)-(2) were not written for the Greek data at all. The descriptions were written for the equivalent English sentences in (3) and (4) below.

(3) a. There remained five soldiers in the camp.

b. Five soldiers remained in the camp.

(4) a. There followed a taxicab.

b. A taxicab followed.

Examples (3) and (4) are taken from Jenkins (1975) and Milsark (1974), respectively, while the description is taken from Lumsden (1988). ${ }^{3}$

\footnotetext{
2) A reviewer observes that $\mathrm{s} /$ he can get the reading 'was coming behind us' for (2b). I can say two things with respect to this remark. First, if a taxi is driven behind some other vehicle, there is an entailment that the taxi is coming behind that other vehicle. The reviewer's point would be problematic for my description, if in (2b) s/he does not share the intuition that the taxi is intentionally driven behind that other vehicle. Second, in Section 6 it is pointed out that the reading 'was coming behind us', on its own, becomes possible for $(2 b)$ in the static mode of presenting information. Crucially, in that meaning example (2b) cannot be part of a sequence of events.

3) According to the description for the English examples, the (b) examples are ambiguous between the two readings while the (a) examples only have the first reading. It would need to be examined, however, whether the (b) examples can only have the first reading if the subject is stressed. If this is so, and we want, at this point, to keep the discussion to sentences with neutral intonation, we will have to say that in a neutral intonation pattern sentences $(3 \mathrm{~b})$ and $(4 \mathrm{~b})$ are unambiguous and cannot have the interpretation of sentences (3a) and (4a), respectively.
} 
Arguably, the semantic difference between the members of the pairs in (1) and (2) is built on predicate type ambiguity. Namely, the two predicates are ambiguous between an unaccusative reading, which is the reading in the (a) examples, and an agentive reading, which is the reading in the (b) examples. The syntactic type ambiguity sometimes appears in the dictionary entries for the two predicates as distinct meanings. Consider the difference between apeminan 'were left'4 and pareminan 'stayed on' for the pair in (1), and the difference between erhotan piso mas 'was coming behind us' and parakolu^use 'stalked' for (2). Given this predicate-type ambiguity, the two members of each pair only appear to involve the same numeration, hence only appear to constitute ideal minimal pairs. For ideal minimal pairs to exist, the syntactic type of the predicate would need to remain constant. What is interesting is that this predicate type ambiguity appears to pattern with a clause level difference manifested across languages. Namely, in Greek it is manifested as a verbinitial/subject-initial distinction, while in English it is manifested as a thereexistential/subject-initial clause distinction; alternatively, as an accented subject/ non-accented subject distinction. The interpretive distinction that is manifested in Greek as a verb-initial/ subject-initial distinction appears to be manifested in English as a there-existential/ subject-initial clause distinction; alternatively, as an accented subject/ non-accented subject distinction. I will discuss the English data in Section 7.

\subsection{Numerations with Arguments Only and the \pm Unaccusative Distinction}

According to the working hypothesis formulated in the previous section, word order variation between verb-initial and subject-initial clauses has to do with syntactic types of predicates. I will next look at more, apparent, minimal pairs where the predicate-type ambiguity is less noticeable at first (cf. (5a-b) and $(6 a-b / c))$. All sentences have neutral, clause-final, stress. For each sentence I also mark the reading it cannot have. With respect to the English translations of the Greek examples, it is important to remember that verb-initial sentences in Greek in some cases correspond to sentences with obligatorily stressed subjects in English. Obligatorily stressed subjects in those cases do not mark subject

4) The unaccusative meno 'remain' in (1a) is an existential predicate. Like other existential predicates, it requires a quantified DP and a property-denoting XP, in this case a PP. Neutral stress is not clause-final, but on the quantified DP. If the property-denoting XP was implicit, as in (1) below, sentence stress would appear to be clause-final.

(1) eminan pede stratiotes

remained-3PL five soldiers-NOM

'There remained five soldiers.' 
focus. The context provided in parentheses for examples (5a) and (6a) indicates that in both cases the event is simultaneous with the event in the clause within parentheses. What this context ensures is that the events described in these two sentences be compatible with a sequence of events text.
(5) a. o Antonis oðizuse (ke eyo kitusa to harti)
the Antonis-NOM was-3SG driving (and I was studying the map)
'Antonis was driving (and I was studying the map).'
*AANTONIS was the driver.'
b. oðiyuse o Antonis
was-3SG driving the Antonis-NOM
'ANTONIS was the driver.'
*AAntonis was driving.'

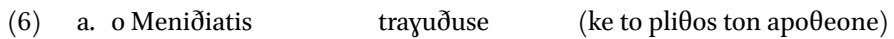

the Menidhiatis-NOM was-3SG singing (and the crowd was cheering frantically)

'Menidhiatis was singing (and the crowd was cheering frantically).'

*'A MENIDHIATIS CD was playing.'

*'MENIDHIATIS would be performing.'

b. trayuðuse o Meniðiatis

was-3SG singing the Menidhiatis-NOM

'A MENIDHIATIS CD was playing.'

*'Menidhiatis was singing.'

c. trayuðuse o Meniðiatis (ke ðe borusa na min pao) was-3SG singing the Menidhiatis-NOM (and I couldn't possibly not go)

'MENIDHIATIS would be performing (and I couldn't possibly not go).'

*'Menidhiatis was singing.'

In (5a) oðiүo 'drive' has the agentive reading 'perform the activity of driving', while in $(5 \mathrm{~b})$ it has the unaccusative reading 'be the driver'. In (6a) tra ruðo 'sing' has the agentive reading 'perform the activity of singing', while in $(6 \mathrm{~b}-\mathrm{c})$ it has an unaccusative reading 'some singer's CD is playing or there is a live performance by that singer'. Because it is not immediately obvious how oðijo 'drive' and trayuðo 'sing' can have unaccusative readings, I will give contexts for this use of the verbs. (a) Suppose that there is music playing on the radio, I ask pios

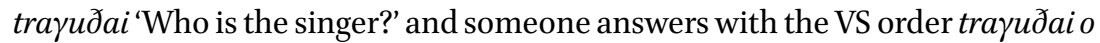
Meniðiatis. All this sentence means is 'MENIDHIATIS is the singer'. (b) Suppose there is an accident, in which a car hits a pedestrian. The police finds out that there were two people in that car, and asks pios oði iruse 'Who was the driver?'. The answer could be the VS order oði izuse o A 'A was the driver'. In these examples oðiүo and trayuðo are stage-level properties and do not involve an Agent. As earlier (1) and (2), the minimal pairs in (5) and (6) are not ideal, because the 
members of each pair involve an agentive and an unaccusative reading of the same predicate. Examples (5) and (6) confirm the hypothesis formulated in the previous section about the patterning between the subject-initial order and the agentive reading of predicates, as well as between the verb-initial order and the unaccusative reading of predicates.

One prediction of the proposed working hypothesis is that with predicates that are not ambiguous between two predicate types only one word order should be possible. It is shown next that the prediction is borne out for both unaccusative-only predicates (cf. (7)-(8)) and agentive-only predicates (cf. (9)(10)). Namely, in neutral sentences unaccusative-only predicates, e.g. vrisko sto Jromo 'bump into' and erhome 'come', can only appear in the verb-initial order (cf. grammatical (7a) and (8a) versus ungrammatical (7b) and (8b), respectively). I characterize vrisko sto ðromo 'bump into' as an unaccusative predicate, because it involves neither agency nor intentionality.

(7) a. me vrike sto ðromo i Raftopulu

me-CL found-3SG on the street-ACC the Raftopulu-NOM

'RAFTOPULU bumped into me.'

b. *i Raftopulu me vrike sto ðromo

the Raftopulu-NOM me-CL found-3SG on the street-ACC

(8) a. ir $\theta$ e i Lena

came-3SG the Lena-NOM

'LENA came.'

b. *i Lena ir $\theta \mathrm{e}$

the Lena-NOM came-3SG

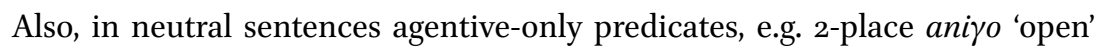
and 3-place vyazo 'take out', can only appear in the subject-initial order (cf. grammatical (9a) and (10a) versus ungrammatical ( $9 \mathrm{~b})$ and (10b), respectively). Sentences (9) and (10) should be embedded in a text with a flow of events.

(9) a. i Patritsia anikse tin porta

the Patricia-NOM opened-3SG the door-ACC

'Patricia opened the door.'

b. *anikse i Patritsia tin porta

opened-3SG the Patricia-NOM the door-ACC

(10) a. i Flora evyale apo tin tsada tis ena pako fotoyrafies the Flora-NOM took-3SG out of her handbag-ACC a bundle photos-ACC

'Flora took out of her handbag a bundle of photos.'

b. *evyale i Flora apo tin tsada tis ena pako fotoyrafies took-3SG out the Flora-NOM of her handbag-ACC a bundle photos-ACC 
The picture that has emerged is summarized in (11) below.

(11) Numerations with arguments only and no sentential operators

a. Verb-initial clauses and subject-initial clauses are in complementary distribution, in the sense that a particular numeration can only be assembled in one of two ways.

b. What determines word order for a particular numeration is the syntactic type of the predicate. Namely, numerations with unaccusative predicates are assembled as verbinitial clauses, while numerations with agentive predicates are assembled as subjectinitial clauses.

A reviewer points out that the claim in (11a) is uninformative, the standard assumption being that each numeration cannot be mapped onto more than one structure with different meaning. If I understand well the reviewer's comment, s/he refers to the general assumption that the subject-initial order involves Topicalization. In line with that assumption, a numeration with a Topic head and an interpretable Topic feature on the subject can only be assembled as a subject-initial clause. In that sense, inclusion of a Topic feature in the numeration predicts the subject-initial order for that numeration as the only possible order, which is why the reviewer characterizes claim (11a) as uninformative. However, I do not think it can be claimed that Topicalization theory predicts word order. Given that (a) subject-initial sentences are the majority of Greek sentences, (b) subject-initial sentences with unstressed subjects in English are equivalent to subject-initial sentences in Greek, and (c) it is possible to topicalize indefinite, quantificational or definite subjects when they are first introduced in discourse, I do not think there is sufficient motivation for taking subject-initial sentences in Greek to involve Topicalization. ${ }^{5}$ What Topicalization theory does is that it inserts in the numeration a feature, i.e. [Topic], that is intended to predict external (or internal, depending on the theory) merge of the topic into a higher position, and hence predict the subject-initial word order. But preverbal subjects are not topics in the first place. Even if the [Topic] feature was motivated, it would need to be accounted for why particular numerations obligatorily include a [Topic] feature, and cannot obtain without the [Topic] feature. This paper shows that only one word order is possible for each numeration and that it can be predicted which one, mainly on the basis of the syntactic type of the predicate. Kechagias (2011), another study that discusses word order in Greek, does not assume or propose a claim like (11a). Kechagias argues that Greek formally realizes, via its word order, two logico-semantic strategies, i.e. a

\footnotetext{
5) What is discussed here is part of a more general issue. It is thought that some semantic or phonetic features are safe markers for particular interpretations. Namely, discourse familiarity for topics and stress for foci. But discourse familiarity, arguably, is not sufficient in order to analyze a preverbal subject as a topic. And as we will see in Section 7 , nor is stress on a DP a sufficient condition for taking that DP to be a focus.
} 
predicative strategy and a non-predicative strategy, where the former surfaces as a non-verb-initial order and the latter one as a verb-initial order. Kechagias's theory observes a pattern between two logico-semantic strategies and two word orders; the pattern is not accounted for, and the two word orders are taken to be in free variation.

Concerning claim (nb), the other reviewer draws attention to predicates which are ambiguous between two syntactic types. S/he points out that if the claim is that all predicates that allow different word order permutations are ambiguous between two syntactic types, we may get one-to-one mappings between numerations and word orders, but this proposal also leads to an unwanted expansion of entries in the mental lexicon. I think that what the reviewer points out could be a problem if it were the case that all predicates could give either order. This is not the case; in fact predicate type ambiguity is observed in a minority of predicates. And predicate type ambiguity is independently motivated (cf. the discussion on unaccusative/causative pairs). I chose to illustrate my theory with the particular predicates, because word order variation with these predicates would be difficult to account for, if one did not notice the ambiguity in predicate type.

\subsection{Across-the-Board Subject-Initial Order for Numerations with Non-Argu- ments}

This section looks at numerations that include non-arguments, as opposed to numerations that only contain arguments (cf. earlier examples (5), (6) and (8) repeated below). ${ }^{6}$

6) The two reviewers disagreed with a number of the grammaticality judgments in examples (5)(8). In particular, the first reviewer considers examples (5d), (6e) and (7b) as grammatical. Also, in (5b) s/he can get the 'perform the activity of driving' meaning, which I mark as ungrammati$\mathrm{cal}$. The second reviewer considers examples $(5 \mathrm{~d}),(6 \mathrm{e})$ and $(8 \mathrm{~b})$ as grammatical. In addition, s/he takes the ungrammatical readings in (5a) and (6a) to be grammatical. So, the two reviewers also differ between themselves in their judgment for five examples, i.e. (5a), (5b), (6a), (7b) and (8b). Next, I will briefly comment on each case where the reviewers' judgment differs from mine.

It is very important to keep neutral, clause-final stress and make no pause between constituents. Notably, examples ( $5 \mathrm{~d}$ ) and (6e) become grammatical, if a pause is inserted before the clause-final non-argument. If so, these sentences do not have neutral intonation, and the clausefinal modifier forms a separate clause by itself.

As pointed out, grammaticality judgments for these sentences are according to whether they could be part of a sequence of events. With respect to examples ( $7 b)$ and $(8 b)$, my intuition is that they are not grammatical if we insert them in a sequence of events. Ungrammatical (8b) has neutral, clause-final stress, as opposed to grammatical (1) below, which has non-neutral, prima facie focal, stress on the clause-final predicate ir $\vartheta e$. Non-neutral stress on the verb in (1) is accidentally clause-final. If the sentence contained more phrases following the verb, the non-neutral 
(5) a. o Antonis oðiyuse (ke eyo kitusa to harti)

the Antonis-NOM was-3SG driving (and I was studying the map)

'Antonis was driving (and I was studying the map).'

*ANTONIS was the driver.'

b. oðizuse o Antonis

was-3SG driving the Antonis-NOM

'ANTONIS was the driver.'

*AAntonis was driving.'

c. o Antonis oðizuse olos anhos

the Antonis-NOM was-3SG driving full of anguish

'Antonis was driving full of anguish.'

*AANTONIS was the driver, full of anguish.'

d. *oðizuse o Antonis olos anhos

was-3SG driving the Antonis-NOM full of anguish

*AANTONIS was the driver, full of anguish.'

*AAntonis was driving full of anguish.'

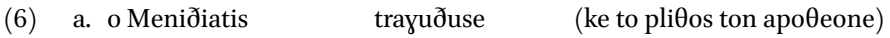

the Menidhiatis-NOM was-3SG singing (and the crowd was cheering frantically)

'Menidhiatis was singing (and the crowd was cheering frantically).'

*AA MENIDHIATIS CD was playing.'

*'MENIDHIATIS would be performing.'

stress would still be on the verb. The interpretation of (1) is along the lines "Lena had to come and she did come".

(1) i Lena IR

the Lena-NOM CAME-3SG

'Lena did come.'

Similarly for $(7 \mathrm{~b})$, where non-neutral stress would fall on the verb or on the final word of the complex predicate vrike sto Jromo. In the latter case the sentence could be a side comment on how come the speaker talked to Raftopulu. For both $(7 \mathrm{~b})$ and $(8 \mathrm{~b})$ non-neutral stress is only compatible with the static mode of presenting information.

With respect to the second reviewer's remark that $s /$ he takes the ungrammatical readings in (5a) and (6a) to be grammatical, I still think this is not possible with clause final neutral stress. That reading becomes possible with clause final non-neutral stress on the verb, as in (2) below, but, again, this is a reading that is only compatible with the static mode.

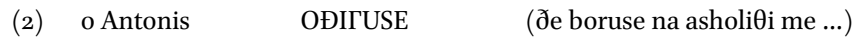

the Antonis-NOM was-3SG DRIVING (could not bother himself with ...)

'Antonis was DRIVING; (he couldn't possibly bother himself with ...).'

Finally, with respect to $(5 \mathrm{~b})$, I still think it cannot have an agentive reading. 
b. trayuðuse o Meniðiatis

was-3SG singing the Menidhiatis-NOM

'A MENIDHIATIS CD was playing.'

*'Menidhiatis was singing.'

c. trayuðuse o Meniðiatis (ke ðe borusa na min pao)

was-3SG singing the Menidhiatis-NOM (and I couldn't possibly not go)

'MENIDHIATIS would be performing (and I couldn't possibly not go).'

*'Menidhiatis was singing.'

d. o Meniðiatis trayuðuse horis mikrofono

the Menidhiatis-NOM was-3SG singing without microphone-ACC

'Menidhiatis was singing without a microphone.'

*AA MENIDHIATIS CD was playing, without a microphone.'

*'MENIDHIATIS would be performing, without a microphone.'

e. *trayuðuse o Meniðiatis horis mikrofono

was-3SG singing the Menidhiatis-NOM without microphone-ACC

*'A MENIDHIATIS CD was playing, without a microphone.'

*'Menidhiatis was singing without a microphone.'

(8) a. irOe i Lena

came-3SG the Lena-NOM

'LENA came.'

b. ${ }^{*} \mathrm{i}$ Lena irӨe

the Lena-NOM came-3SG

c. ${ }^{*}$ ir $\theta$ e i Lena me tin proini ptisi

came-3SG the Lena-NOM with the morning flight-ACC

d. i Lena ir $\quad$ e $\quad$ (5 ores aryotera) me tin proini ptisi

the Lena-NOM came-3SG (5 hours later) with the morning flight-ACC

'Lena came ( 5 hours later) with the morning flight.'

In making sense of the data it is important to remember that, where possible, the sentences under examination should be taken to form part of a sequence of events. With that in mind, prima facie it appears that adding non-arguments to numerations with agentive predicates does not make a difference, in the sense that we still get subject-initial clauses (cf. grammatical (5c) and (6d)), while adding non-arguments to numerations with unaccusative predicates does make a difference, in the sense that non-arguments are not allowed in verbinitial clauses (cf. ungrammatical (5d), (6e) and (8c)). It appears that numerations with unaccusative predicates and non-arguments can only be assembled as subject-initial clauses (cf. (8c)). However, grammatical (8d), inserted in a sequence of events, no longer 'states what happened', as (8a) does; somehow it appears to involve, if not agenthood, at least attribution of intention to 
an entity, along the lines 'Lena chose to arrive ( 5 hours later) with the morning flight'. The question arises why grammatical (5c) and (6d) cannot optionally have the reading that is marked ungrammatical in each case. I think this is so because the readings 'be the driver' and 'perform/ some singer's CD is playing', respectively, are not compatible with the use of adjuncts. The apparent incompatibility of non-arguments with unaccusative predicates in a sequence of events mode, as illustrated by the ungrammatical readings for $(5 \mathrm{c})$ and $(6 \mathrm{~d})$ and the intentional reading for the predicate in $(8 \mathrm{~d})$, needs to be further explored.

To sum up, in Sections 3.1-3.3 I have looked at sentences forming part of sequences of events and have defended the hypothesis that a particular numeration can be assembled in only one way, i.e. as a verb-initial clause or as a subject-initial clause. The 'environment' for the complementary distribution between the two word orders is the syntactic type of the predicate. In order to be able to see/ show this picture of complementary distribution, I had to make use of the distinction 'numerations with arguments only versus numerations with non-arguments'. Crucially, the complementary distribution between the two word orders does not depend on some contextual factor. Namely, the fact that the subject DP in verb-initial clauses does not necessarily refer to an individual that is not already introduced in context (cf. (5b)) implies that it is not absence of discourse-linking ${ }^{7}$ that is required for the verb-initial order. Also, while it is true that, if we were asked to imagine a context for $(8 \mathrm{a})$, we would easily think up a context where the subject is not discourse-linked, the same sentence can equally naturally form part of a sequence of events like 'we got up early, LENA came and we started our journey', where Lena is d-linked. This is evidence that it is not the context that determines the choice between the verb-initial and the subject-initial word order.

\section{The Semantic Interpretation of Verb-Initial and Subject-Initial Clauses}

This section looks at the semantic interpretation of verb-initial and subjectinitial clauses in Greek. It is argued that the semantic interpretation of verbinitial versus subject-initial clauses can be described in terms of a distinction between eventuality existentials versus predication clauses. The former working hypothesis that a particular numeration can be assembled as only one of the two word orders, i.e. as a verb-initial clause or as a subject-initial clause, now takes the form in (12).

(12) A particular numeration can be assembled in only one way, i.e. as an eventuality existential or as a predication clause, but not as either.

7) I am extending Pesetsky's (1987) notion of discourse-linked phrases to cover all DPs, and not only interrogative phrases. A discourse-linked DP refers to an already familiar discourse entity. 
The complementary distribution of the verb-initial order and the subjectinitial order is less of a puzzle now. It reduces to the complementary distribution between eventuality existentials and predication clauses. This complementary distribution is expected, if, as argued, what is at issue is a semantic clause type distinction. The verb-initial/ subject-initial distinction is the syntactic manifestation in Greek of the semantic clause type distinction. It is also easier to understand why the \pm unaccusative predicate type distinction is the basis of, and derives, the semantic clause-type distinction than it was to understand why the \pm unaccusative predicate type distinction would be the basis of a word order distinction.

\subsection{Kuroda's (1972, 1992) Distinction between Thetic and Categorical Judgments}

The semantic opposition manifested with the verb-initial versus subject-initial word order distinction in Greek is not new in linguistics. It seems to be no different from Kuroda's $(1972,1992)$ logico-semantic distinction between thetic and categorical sentences. According to Kuroda, "Thetic sentences are used to report perception of a situation of a certain type, while categorical sentences draw attention first to an entity and then a property is attributed to that entity". The semantic difference between thetic and categorical sentences is manifested in Japanese, a fixed word order language, with an enclitic marker on the always preverbal subject ( $g a$ for thetic sentences versus $w a$ for categorical sentences). Sasse (1987) discussed the syntactic manifestations of Kuroda's distinction across languages; he argued that this distinction is syntactically manifested as a verb-initial vs. subject-initial distinction in some languages, Greek included, observing (p. 537), as noted in Section 1, that "VS order is less frequently found in sentences having full objects". There are two differences between Sasse's description of the Greek data and the description in this paper. Namely, (a) for Sasse all intransitives yield the VS order, while according to the description in this paper only unaccusatives yield the VS order. (b) Sasse includes the order PronominalObject-Verb-Subject in VS sentences, while I take the PronominalObject-Verb-Subject order to be an example of the OVS order with an object pro in clause-initial position. One piece of evidence why we should not put together sentences with pronominal objects in the order PronominalObject-Verb-Subject and VS sentences with unaccusative verbs is because the two types differ in interpretation. Namely, in Kuroda's and Sasse's terms, in the first type a property is attributed to the entity the object refers to, while the second type is interpreted as a thetic sentence.

This paper revisits the logico-semantic distinction put forward by Kuroda. A different description for the same intuitive distinction is presented in Section 4.2, where it is proposed that what is involved is a distinction between eventu- 
ality existentials and predication clauses. It is also argued that this distinction is grounded on the extralinguistic distinction between transformation and action (cf. Jullien 1996, 2012). The different conception of the distinction in Kuroda's work and in this paper is discussed (cf. also the related discussion in Section 6 on the two modes of presenting information and how these interact with the distinction between eventuality existentials and predication clauses).

\subsection{A New Description for a Known Distinction: Eventuality Existentials vs. Predication Clauses}

My intuition about the Greek data is that the difference in interpretation between verb-initial sentences and subject-initial sentences in Greek is in essence captured by Kuroda's distinction between thetic and categorical sentences. It is proposed that this semantic difference is more adequately, as well as more transparently, described as a distinction between eventuality existentials and predication clauses (cf. claim (13)). The description I give for predication clauses is no different from Kuroda's description for categorical sentences, i.e. that predication clauses draw attention first to an entity and then a property is attributed to that entity.

(13) a. Verb-initial clauses in Greek are interpreted as eventuality existentials.

b. Subject-initial clauses in Greek are interpreted as predication clauses.

Although Kuroda's description thetic vs. categorical sentences and the description eventuality existentials vs. predication clauses address the same semantic distinction in two different languages/ across languages, it is useful to point out two differences between these two approaches. First, Kuroda uses numerations with the same predicate, i.e. 'sleep', to illustrate the two sentence types. This shows (a) that the distinction he proposes does not derive from a predicate type distinction. And (b) that Kuroda's description of this semantic distinction at the same time involves the mode of presenting information distinction, and Kuroda does not tease apart the two distinctions. Second, the fact that Kuroda describes thetic sentences as 'used to report perception of a situation of a certain type' supports the hypothesis that Kuroda actually describes thetic sentences in the static mode. If, as argued in Section 7 , the proposed semantic clause type distinction is universal, the Greek-specific claim in (13) should be replaced with the more general claim in (14).

(14) a. Eventuality existentials are syntactically realized in Greek as verb-initial clauses.

b. Predication clauses are syntactically realized in Greek as subject-initial clauses.

The patterning together of word orders and interpretations, as in (13) and (14), cannot explain why it is not possible to have the same numeration in either 
word order/ interpretation. As argued in Sections 3.1 and 3.2, verb-initial clauses obtain with unaccusative predicates, while subject-initial clauses obtain with agentive/intentional predicates. The complementary distribution of the two word orders is in essence the complementary distribution between eventuality existentials and predication clauses. This, in turn, derives from the predicate types that constitute the core of these clause types, i.e. unaccusative predicates and agentive/intentional predicates, respectively (cf. claim (15)). The meaning of unaccusative predicates is compatible with the interpretation of eventuality existentials, and the meaning of agentive/intentional predicates is compatible with the interpretation of predication clauses.

(15) The \pm unaccusative distinction is the basis for the distinction between eventuality existentials and predication clauses.

Claim (15) is not undermined by the fact, discussed in Section 3.3, that in a sequence-of-events mode unaccusative predicates are not compatible with non-arguments, nor by the fact that in the static mode of presenting information, agentive/intentional predicates can also derive eventuality existentials, preferably if the numeration includes a sentential operator, optionally otherwise (cf. Sections 5 and 6). Because the typical case of verb-initial clauses in Greek involves unaccusative predicates, which are known to describe either a state or a change of state, it is proposed that, in all cases, verb-initial clauses are interpreted as eventuality existentials. In addition, this interpretation seems natural for clauses in the static mode of presenting information. The claim is that it is only this clause type that involves an existential closure operator over events. Subject-initial clauses, on the other hand, are described as predication clauses. As already pointed out, the term 'predication' is not used here in its generally accepted syntactic sense, i.e. to describe the grammatical relationship between a predicate and a subject. The term is used in its philosophical sense, to describe cases where a property is attributed to an entity. And these are a subset of predicate-subject relations.

In standard semantic terms, in all sentences it is the predicate that is saturated by its arguments in a fixed order. It is next claimed that this is not the case for all sentences. In particular, that the interpretation of eventuality existentials and predication clauses has to do with distinct semantic derivations for the two clause types. The proposed derivations should be of a general form, so as to capture the varied syntactic manifestations of this distinction across languages (cf. Section 7). I advance the proposal in (16)-(17) for the semantic derivation of eventuality existentials and predication clauses.

(16) In predication clauses the subject DP is interpreted in the same way as generalized quantifiers, i.e. as a second order property (semantic type $\langle\langle e, t\rangle, t\rangle$ ). 
(17) a. In eventuality existentials the entity denoted by the subject DP (semantic type $\langle e\rangle$ ) saturates the property denoted by the predicate (semantic type $\langle e, t\rangle$ ).

b. In predication clauses the property denoted by the predicate (semantic type $\langle e, t\rangle$ ) saturates the second order property denoted by the subject DP (semantic type $\langle\langle e, t\rangle, t\rangle$ ).

The two types of semantic derivation for a clause appear to correlate with the distinction between events and individuals. One can talk about events that took place or talk about individuals and attribute properties to those individuals. The properties attributed to those individuals amount to events that characterize those individuals. The proposal for the semantic derivation of subject-initial clauses (but also of CL(itic)-L(eft)-D(islocation) clauses) is already advanced in Agouraki (2009, 2010a). What is 'felt' as predication is precisely the result of a first-order property saturating a second-order property. It is proposed that the interpretation of predication clauses is along the following lines: 'There is an entity $\mathrm{x}$ such that property $\mathrm{p}$ is attributed to $\mathrm{x}$ '. A predication clause is true in world $w$ iff a particular property characterizes a particular entity in that world. It is also proposed that the interpretation of eventuality existentials is along the following lines: 'There is an event of VERB-ing, and this event's participant is $\mathrm{x}$ '. An eventuality existential clause is true in world $w$ iff there is such an event in that world.

As one of the reviewers observes, the proposal in (16) and (17) makes the prediction that only things of type $\langle e\rangle$ can appear in eventuality existentials. The reviewer mentions example (18) below as a counterexample.

(18) irfan meriki portoyali

came-3PL some Portuguese-NOM

'There came some Portuguese people.'

The reviewer's point is well taken. I think it is interesting, though, to juxtapose example (18) and examples (19a, b) below with earlier examples (8a, b, d). What we see is that examples (18), (19a-b) are parallel to examples $(8 a, b, d)$, respectively, where the argument was a non-quantified DP. The same factors that determined word order in (8) determine word order in (18) and (19).

(19) a. *meriki portoyali irOan some Portuguese-NOM came-3PL

b. meriki portoyali irOan me tin proini ptisi some Portuguese-NOM came-3PL with the morning flight-ACC

'Some Portuguese people came with the morning flight.'

What the data could suggest is that the semantic type of a DP does not depend on the quantified versus non-quantified status of the DP but on whether it is the subject of predication or not. While the interpretation of subject DPs 
as second-order properties is standardly accepted only for quantified DPs, it could be the case that the interpretation of quantified DPs in subject position is only an example of a more general structure, i.e. the interpretation of DPs in predication. If so, the interpretation of quantified DPs in positions other than the subject of predication should be re-examined.

Obviously, I am not claiming that quantified DPs that are not the subject of a predication structure are interpreted as entities (semantic type $\langle e\rangle$ ). The quantified DP in (18) certainly has no fewer problems than quantifiers in object position are known to have. It could be examined whether the quantified DP in (18) involves type-shifting or a non-saturating mode of composition, like Chung and Ladusaw's (2004) (predicate) restriction. This is certainly not the place to address this question.

Another interesting question is why it should be the case that a numeration with an unaccusative predicate and a non-argument can only be assembled as a predication clause, if at all (cf. the contrast between grammatical ( $8 \mathrm{~d}$ ) and the ungrammatical reading for $(5 \mathrm{c})$ and $(6 \mathrm{~d}))$. A possible working hypothesis is that the reason is semantic and has to do with how the meaning of the modifier is combined with the meaning of the predicate. If the modifier is saturated by the property denoted by the predicate, and results in a new, combined property, it could be that the new property no longer involves an unaccusative predicate. The only possibility is for the new property to saturate a second order property. A reviewer suggests that looking at function composition or a richer type theory might be a way out.

The claim for a semantic clause-type distinction between eventuality existentials and predication clauses is based (a) on the existence of an interpretive distinction, syntactically manifested in Greek as a distinction between verb-initial and subject-initial clauses, (b) on the complementary distribution between the two word orders, (c) on the universality of this interpretive distinction, irrespective of its syntactic manifestation (cf. Section 7), (d) on the correlation between the syntactic manifestation of this interpretive distinction in a language and clause structure properties of that language, and (e) on the patterning between this distinction and the \pm unaccusative distinction. Additional, extra-linguistic, support for the distinction between eventuality existentials and predication clauses comes from an examination of how we perceive and analyze the external world. In particular, it is proposed that the semantic clause-type distinction between predication clauses and eventuality existentials patterns together with the philosophical distinction between action and transformation in human behavior and the course of nature (cf. Jullien 1996, 2012). ${ }^{8}$ This is a distinction between something that can be attributed to a

8) I would like to thank Aristi Proussioti for bringing Jullien (2012) to my attention. It was for a non-linguistic reason, but her suggestion has served many purposes. 
particular person and be identified as his or her action and a regulated and continuous process or the course of nature. There are three properties that distinguish an action from a transformation, i.e. time, locality and attribution to a subject. In particular, an action is (a) momentaneous, even if this moment lasts for a long time (e.g. conquering a city); (b) it is local; and (c) it is explicitly attributed to a subject. Given that an action is local, momentaneous and is attributed to a subject, it is set apart from the normal course of events. A transformation, on the other hand, (a) cannot be momentaneous, but takes time and involves a process; (b) it is not local but global, in the sense that something undergoes transformation as a whole, even if it superficially appears that only some part is affected; and (c) the involvement of a particular subject in a transformation is very little, and can only be indirect, as the main role in bringing about the transformation is played by the surrounding environment. The transformation as such cannot be seen; we only see its results. Using this objective distinction that can adequately describe human behavior and the course of nature, Jullien argues that Chinese thought values transformations and presents history as a series of transformations, while Western thought values actions and presents history as a series of actions. Given that in history there appears to exist the option of 'noticing' actions or 'noticing' transformations, it will also be interesting to think whether we, as speakers, have a similar option when we talk about human behavior or the course of nature. The issue is addressed in Section 7. The patterning between the proposed clause-type distinction and philosophical distinction between tranformation and action is described in $(20)$.

(20) a. Eventuality existentials portray transformations.

b. Predication clauses portray actions.

To sum up the pieces of the Greek VS/SV puzzle, these include the extra-linguistic, philosophical distinction between transformation and action, the semantic distinction between eventuality existentials and predication clauses, the syntactic distinction between verb-initial and subject-initial clauses, which is the syntactic realization of the semantic distinction in Greek, the complementary distribution of the two word orders, and the \pm unaccusative distinction. The link that puts all this together is the \pm unaccusative distinction. Given (20), the patterning between the eventuality existential/ predication clause distinction and the \pm unaccusative distinction makes sense. The cognitive terms transformation and action describe human behavior or the course of nature. The terms unaccusative or agentive, on the other hand, describe predicate meaning. The semantic clause type distinction between eventuality existentials and predication clauses is the sentential distinction that brings together the cognitive dis- 
tinction between transformations and actions with the lexical level predicate type \pm unaccusative distinction.

It could be pointed out that the cognitive distinction between transformation versus action and the semantic clause type distinction between eventuality existentials versus predication clauses are not fully identical, and that their difference is not accounted for simply by taking into consideration the difference between cognition and language. Namely, the notion predication is weaker/ more general than the notion action, in the sense that predication need not involve an action. It will need to be explained why the weaker/ more general notion of predication is used instead of the stronger/ narrower notion of action. This is addressed in Section 6. At the same time, the notion eventuality existential is weaker/more general than the notion transformation, in the sense that it overlooks the connection with unaccusativity and allows, under certain circumstances (cf. Sections 5 and 6), for eventuality existentials with agentive predicates. It will need to be explained why the weaker/ more general notion of eventuality existential is used instead of the stronger/ narrower notion of transformation. This is again addressed in Section 6. I will next present the main points of that discussion. The three distinctions that seem to interact are the following: transformation vs. action, entity vs. event (transformation or action) and sequence of time intervals vs. a single time interval. As pointed out earlier, one can talk about events that took place or talk about individuals and attribute properties to those individuals. The properties attributed to those individuals involve events that characterize those individuals. Events, be they transformations or actions, may, or may not, form part of sequences of events. For a property or event attributed to an entity to count as an action, that property/event must be part of a sequence of events. So, the subject-initial order in (21) involves an action, if this event forms part of a sequence of events. If, on the other hand, the event described in (21) is not part of a sequence of events, the sentence can only be uttered to give the hearer an indication of that person's character, in which case the sentence only involves predication and does not describe an action. In the first use, (21) involves predication and, at the same time, describes an action.

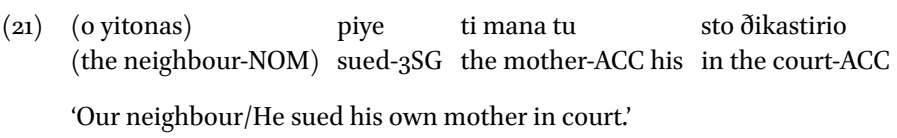

Similarly, the verb-initial order in (22) may, or may not, form part of a sequence of events. If there is no sequence of events, the verb-initial order is only interpreted as an eventuality existential, and does not involve a transformation. If there is a sequence of events, on the other hand, the verb-initial order involves an eventuality existential and, at the same time, describes a transformation. 


\section{(22) ðiekopisan i sinomilies \\ were-3PL adjourned the talks-NOM \\ 'Talks were/ have been adjourned.'}

To conclude, because the interpretation of verb-initial and subject-initial clauses is 'weaker' when the events they describe do not form part of a sequence of events, I have chosen to describe the interpretations of verb-initial and subject-initial clauses as those are minimally shaped when verb-initial and subjectinitial sentences are not in a sequence of events, i.e. as eventuality existentials and predication clauses, respectively.

In sentences which are not part of a sequence of events, and where the 'action' component is, therefore, removed from the interpretation of subjectinitial sentences, it is possible to have predication clauses with objects. More specifically, on the basis of evidence presented in Agouraki (1992,1993), where it is shown that $\mathrm{CL}$ (itic)-L(eft)- $\mathrm{D}$ (islocated) objects have A-properties, it is claimed that the proposal for the interpretation of subject-initial sentences as predication clauses extends to sentences with CLitic-Left-Dislocation (cf. (23)).

\footnotetext{
(23) ton patera sas ton ektimai olos o kosmos

the father-ACC your him-CL respect-3SG whole the world-NOM

'Your father enjoys everyone's respect.'
}

The evidence for CLLDed objects having A-properties relates to binding, pseudo-relatives, control verbs, the existence of subject+verb idioms and discontinuous idioms, quirky subjects and subject-oriented adverbs. Agouraki (1992, 1993) shows that in all these cases there is no asymmetry between subjects and CLLDed objects. The first three are syntactic pieces of evidence, while the remaining four are semantic pieces of evidence. More specifically, CLLDed objects can act as probes in binding, pseudo-relatives and control, while nonCLLDed objects cannot. Subject+verb idioms, discontinuous idioms and quirky subjects (e.g. the Experiencer argument of aresi ' like', lipi 'miss') have obligatory CLLD. And subject-oriented adverbs can establish a relation to CLLDed objects. Arguably, these semantic pieces of evidence for the claim that CLLDed objects have A-properties are at the same time pieces of evidence for the claim that in CLLD a property is predicated of the object. It is possible to give one more piece of evidence. Namely, English passive sentences are usually translated in Greek as CLLD sentences (cf. (24)).

(24) a. The article was read by many students.
b. to arӨro to ðiavasan poli fitites the article-ACC it-CL read-3PL many students-NOM
'The article was read by many students.' 
A different proposal for an apparently related distinction, that is described as a distinction between two formal ways of presenting information, in essence two logico-semantic strategies, is put forward in Kechagias (2011). The proposed distinction is between a predicative and a non-predicative mapping, realized as a non-verb-initial order and a verb-initial order, respectively. The argumentation for this proposal is identical to Kuroda's basic argumentation in a series of papers. The distinction is not necessarily intended to cover the same range of data as the distinction between eventuality existentials and predication clauses proposed in this paper.

\section{Sentential Operators and the Distinction between Eventuality Existen- tials and Predication Clauses}

So far I have discussed data with neutral, clause-final stress and no sentential operators, whether actual world operators or possible world operators. Two issues arise. (a) We need to examine the word order/ clause type for numerations that include a sentential operator. And (b) it needs to be checked whether it is at all possible for predicates other than unaccusative predicates to derive eventuality existentials. If there are such cases, they need to be accounted for. The two questions/issues are not unrelated, in the sense that sentential operators appear to be a 'mechanism' by means of which numerations with agentive/intentional predicates may be assembled as eventuality existentials. It is also claimed that sentential operators are a subpart of a more general 'mechanism', i.e. the static mode of presenting information. This is discussed in section 6 , where it is shown that numerations with agentive/intentional predicates in the static mode of presenting information can be assembled as eventuality existentials.

\subsection{Actual World Operators}

By 'actual world' operators I mean operators that select propositions situated in the actual world. These include factive, relative and adverbial (a subset of temporal, causal or concessive) operators/complementizers.

\subsubsection{Factive Complements}

The contrast I am drawing attention to next is between the embedded clause in (25a) and the corresponding matrix clause in (25c). Namely, the verb-initial factive complement in (25a) is fine, although this is a numeration with an agentive predicate, while the corresponding matrix verb-initial clause in $(25 \mathrm{c})$ is not equally acceptable. In fact, the same numeration, as a factive complement, can 
alternatively yield a subject-initial word order (cf. (25b)), which is, however, less common than the verb-initial order in (25a).

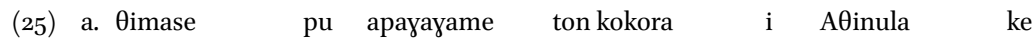
remember-2SG that kidnapped-1PL the cockerel-ACC the Athinula-NOM and

еуо ?

I-NOM

'Do you remember when Athinula and I kidnapped the cockerel?'

b. Aimase pu i A Ainula ke eyo apayayame

remember-2SG that the Athinula-NOM and I-NOM kidnapped-1PL

ton kokora ?

the cockerel-ACC ?

'Do you remember when Athinula and I kidnapped the cockerel?'

c. *apayayame ton kokora i Aөinula ke eyo

kidnapped-1PL the cockerel-ACC the Athinula-NOM and I-NOM

'Athinula and I kidnapped the cockerel.'

\subsubsection{Relative Clauses}

The verb-initial relative clause in (26a) is fine, although this is a numeration with an agentive predicate. Notably, the corresponding matrix verb-initial clause in (26c) is not acceptable as a neutral sentence with clause-final stress; it has to be stressed on the object secondary predicate ataksinomita 'unclassified', and preferably also needs an object clitic in addition to the overt object (i.e. obligatory clitic-doubling). As was the case with factive complements, the same numeration, as a relative clause, can alternatively yield a subject-initial word order (cf. (26b)), which is, however, less common than the verb-initial order in (26a).

(26) a. ta egrafa pu afise ataksinomita i prokatohos tu the documents-NOM/ACC that left-3SG unclassified the predecessor-NOM his 'the documents his predecessor hadn't classified'

b. ta egrafa pu i prokatohos tu afise ataksinomita the documents-NOM/ACC that the predecessor-NOM his left-3SG unclassified 'the documents his predecessor hadn't classified'

c. (ta) afise ATAKSINOMITA ta egrafa i prokatohos (them-CL) left-3SG UNCLASSIFIED the documents-ACC the predecessor-NOM tu his

'His predecessor had not classified the documents.' 


\subsubsection{Adverbial Clauses}

The contrast here is between the grammatical adverbial clause in (27a) and the ungrammatical corresponding matrix clause in (27b). The clauses in (27) have an agentive predicate in the verb-initial order.

(27) a. prin ton ioӨetisi i yria

before him-CL adopt-3SG the old woman-NOM

'Before the old woman adopted him.'

b. *ioӨetise i yria to Yani adopted-3SG the old woman-NOM the Yanis-ACC

\subsubsection{Summary}

To sum up, the presence of actual world operators (factive, relative or adverbial) is able to yield the verb-initial order for a numeration with an agentive predicate. The obvious question is why these actual world operators have this capacity. The reason could have to do with the fact that sentences with these operators do not mark events in a sequence of events; they cannot, therefore, portray actions, as is common usage for their agentive/intentional predicates. This could be why their numerations are assembled as verb-initial clauses and are interpreted as eventuality existentials.

\subsection{Possible Worlds Operators}

Additional categories that appear to be able to yield eventuality existentials with agentive/intentional predicates, which would not otherwise be licensed, include Negation, Possibility, Necessity, and Emphasis on the verb (cf. (28a), (29), (30) and (31), respectively). Predication clauses are also possible with these categories (cf., for instance, $(28 \mathrm{~b})$ ). This fact does not undermine the validity of the contrast between the grammaticality of (28a) and the unacceptability of (28c), where no operator is used.

(28) a. ĐEN (to) ðiapraymateftike to sheðio o proeðros NOT (it-CL-ACC) negotiated-3SG the plan-ACC the president-NOM

'The President did not conduct negotiations on the plan.'

b. o proeðros ĐEN (to) ðiapraymateftike to sheðio the president-NOM NOT (it-CL-ACC) negotiated-3SG the plan-ACC

'The President did not conduct negotiations on the plan.'

c. ?ðiapraymateftike to sheðio o proeðros negotiated-3SG the plan-ACC the president-NOM 
(29) bori na ðiapraymateftike to sheðio o proeðros could-3SG be COMP negotiated-3SG the plan-ACC the president-NOM

'The President may have conducted negotiations on the plan.'

(30) prepi na ðiapraymateftike to sheðio o proeðros must-3SG COMP negotiated-3SG the plan-ACC the president-NOM

'The President must have conducted negotiations on the plan.'
ĐIAPRAГMATEFTIKE to sheðio
o proeðros
(it-CL-ACC) NEGOTIATED-3SG
the plan-ACC the president-NOM

'The President DID conduct negotiations on the plan.'

The categories Negation, Possibility, Necessity, and Emphasis on the verb function as a natural class in licensing eventuality existentials. Negation is generally characterized as a propositional operator. As far as I know, Emphasis on the verb is not analyzed as an operator. I am proposing that Negation and Emphasis (on the verb) involve Possibility or Necessity, at least in the examples and cases under examination here. More specifically, I am proposing that (28a) is interpreted as 'the set of worlds in which the President did not conduct negotiations on the plan is larger than the set of worlds in which the President conducted negotiations on the plan'. And that (31) is interpreted as 'the set of worlds in which the President conducted negotiations on the plan is larger than the set of worlds in which the President did not conduct negotiations on the plan'. Negation and Emphasis on the verb function as mirror images of each other. Alternative interpretations for (28a) are along the following lines: 'The President could not or should not have conducted negotiations on the plan, and he did not conduct negotiations on the plan'. Along similar lines, alternative interpretations for (31) could be 'The President could have or should have conducted negotiations on the plan and he conducted negotiations on the plan'. The two interpretations for Negation and Emphasis on the verb involve Possibility or Necessity. On the basis of the claim for the interpretation of examples (28a) and (31), I am putting forward the working hypothesis that the four categories that license eventuality existentials with agentive predicates reduce to two, i.e. Possibility and Necessity. If so, the natural class involved is that of modal operators. I have chosen to refer to the modal operators as 'possible worlds operators' for two reasons. (a) To differentiate them from the operators discussed in Section 5.1. And (b) in order to include the Question operator (cf. (32)), which also licenses eventuality existentials. Yes-no questions, and not just disjunctive questions, are sentences where possible worlds are presented but no modal relation is introduced.

(32) su ipe tipota o kirios Kremopoulos? you-CL-GEN told-3SG anything-ACC the mister Kremopoulos-NOM ?

'Has Mr. Kremopoulos told you anything?' 
Arguably, the interpretation of the yes-no question in (32) involves the set of worlds in which Kremopoulos said something to the hearer and the set of worlds in which Kremopoulos said nothing to the hearer. As shown by the interpretation, eventuality existentials are compatible with yes-no questions; we do not need to assume that yes-no questions in Standard Greek involve V-to-C raising.

\subsection{Stress on the Predicate: A Modal Marker (or a Telicity Marker)}

Because I have underlined the fact that the scope of this paper is word order in neutral sentences, which are expected to involve clause-final stress, I would like to resume the discussion about apparently non-neutral stress on the predicate, initiated in the previous section (cf. example (31)). It was argued that stress on the predicate involves a modal operator (i.e. Possibility or Necessity), and that in the case of agentive/intentional predicates it is this modal operator that licenses the numeration as an eventuality existential. I will next look at a different set of cases involving eventuality existentials with stress on the predicate (cf. (33-34)). Namely, the numerations for these examples cannot be assembled as sentences with clause-final stress (cf. ungrammatical (33a) and (34a)), even though the numerations involve unaccusative predicates, which are known to derive eventuality existentials. The obvious question is why a subset of unaccusative predicates should require obligatory stress on the predicate. It will also be of interest to consider whether these data relate to the earlier claim that nonneutral stress on the predicate involves a modal operator.

(33) a. *anevike to psomi

rose-3SG the bread dough-NOM

b. ANEVIKE to psomi

ROSE-3SG the bread dough-NOM

'The bread dough has risen.'

c. anevike se misi ORA to psomi

rose-3SG in half an HOUR the bread dough-NOM

'The bread dough rose in half an hour.'

(34) a. *meyalosan i yonis mu

grew-3PL old the parents-NOM my

b. METALOSAN i yonis mu

GREW-3PL OLD the parents-NOM my

'My parents have grown old.'

We can begin to make sense of the requirement for stress on these predicates if we contrast example (33b) with example (35), which has the 'same' predicate but neutral clause-final stress. 
(35) anevikan i times went up-3PL the prices-NOM

'PRICES have gone up.'

The contrast between (33b) and (35) suggests that obligatorily stressed unaccusative predicates are telic unaccusative predicates with incremental themes; it appears that Greek uses stress to disambiguate unaccusative predicates that are ambiguous between an atelic reading (cf. (35)) and a telic reading (cf. (33)). In the absence of a frame adverbial (e.g. in half an hour) to mark the telic reading and bear sentence stress (cf. (33c)), stress on the verb becomes obligatory. This working hypothesis is confirmed with more unaccusative predicates that are ambiguous between an atelic and a telic reading (cf. vrazo 'boil', malakono 'soften' etc.). In the telic reading, what is described is the course of nature. It is the normal course of events for a dough containing yeast to rise or for a human being to grow older. In that sense the dough must rise and a person must grow older, unless some contrary force comes into play. ${ }^{9}$ If so, the telic reading of unaccusative predicates is not unrelated to the interpretation of the modal operator that is marked with non-neutral stress on the verb (cf. the discussion in the previous section).

Finally, a reviewer raises a point with respect to the inclusion of stressed verbs in numerations. The cases discussed in this section do not involve neutral clause-final stress, which clearly would be determined at the syntax-phonology interface. With respect to example (31) of Section 5.2, stress on the verb is a marker of a modality operator. Arguably, either the stressed verb as such, with its modal interpretation, is included in the numeration, or an unstressed verb and a null modal operator are included in the numeration and some rule is added to the PF component so as to derive stress on the verb. It is not obvious

9) A reviewer observes that s/he does not agree with the grammaticality contrast between example (33a) and example (35). S/he remarks that the oddness in (33a) is attributed to the non-literal interpretation of the subject in (33a), in the sense that prices are expected to rise, whereas bread is not. It is not obvious to me why the interpretation of the subject in (33) is non-literal, if we actually see the bread dough changing shape. Also, bread dough with yeast should rise, and is, therefore, expected to rise. I think that it is not a question of non-literal versus literal meaning of the subject, but a question of telic versus atelic reading of unaccusative predicates. Actually, (35) is OK only if the predicate is interpreted as atelic; the speaker observes an increase in prices, which s/he did not expect. If, on the other hand, the prices were expected to rise, and they did, as is the context the reviewer describes, I think it would be more natural to have stress on the verb as in (1) below.

(1) ANEVIKAN i times

WENT UP-3PL the prices-NOM

'Prices HAVE gone up.' 
to me that the second option is optimal or that the PF rule is easy to describe, which is why I include the stressed verb, with its interpretation, in the numeration. With respect to examples (33b) and (34b), these are precisely cases where stress on the unaccusative predicate marks telicity, which, arguably, justifies inclusion of a stressed verb in a numeration; stress on the verb could not possibly be determined by some rule in the PF component. If it turns out, as suggested, that stress on telic unaccusative predicates also involves a modal operator, then stress on telic unaccusatives should be treated as the rest of cases where a modal operator is marked with stress on the predicate.

\section{Modes of Presenting Information and the Distinction between Eventual- ity Existentials and Predication Clauses}

Sentences with sentential operators cannot be part of a sequence of events. In that sense, sentential operators fall under a more general 'mechanism', i.e. the static mode of presenting information. The 'effect' of the static mode on word order is discussed in this section. It is shown in which other cases, apart from numerations with sentential operators, numerations with agentive/intentional predicates can be assembled as eventuality existentials. It is also examined whether the static mode has an effect on numerations with unaccusative predicates.

\subsection{Modes of Presenting Information}

Agouraki (2011) draws a complementizer layer distinction which has to do with the speaker's choice with respect to whether or not a sentence participates in an external flow of time. This distinction between the presence versus absence of an external flow of time is described as a distinction between a dynamic versus a static mode of presenting information. In the static mode of presenting information the speaker zooms in on a particular point in time or time interval and describes the state-of-affairs at that point in time or time interval. This description includes events that take place at that time interval, as well as anterior events. In the dynamic mode of presenting information, on the other hand, the speaker presents a sequence of events in chronological order. In the dynamic mode of presenting information, because there is an external flow of time, the semantic, clause type distinction between eventuality existentials and predication clauses takes the more specific form of a distinction between transformations and action clauses. To give an example of the static mode versus dynamic mode distinction, an anterior event is marked with the perfect in the static mode of presenting information, and with past tense in the dynamic mode of presenting information. Not only in dialects or languages that lack the perfect, 
but also in dialects or languages that have the perfect, an anterior event in the static mode can alternatively be marked with past tense, provided that it is clear from the preceding text that the speaker makes use of the static mode of presenting information. The distinction between a dynamic and a static mode of presenting information involves a complementizer-level head, i.e. the Modeof-Presenting-Information head and the corresponding MPIP(hrase). The MPI head can have one of two values, i.e. [dynamic mode] or [static mode].

To go back to the dynamic mode of presenting information, the sequence of events has a starting point that needs to be anchored at a particular point in time for the sequence of events to kick off. It is often the case that a description, however minimal, of the state-of-affairs at the starting point of the sequence of events is provided. In the absence of a more or less definite point in time supplied by an adverbial modifier or a state-of-affairs description functioning as a temporal anchor, it is the first eventuality in a sequence of events that functions as the required temporal anchor for the dynamic mode of presenting information. Within any minimal self-sufficient text the two modes of presenting information usually coexist. More specifically, as already pointed out, the static mode may provide the temporal anchor for the dynamic mode. It is also the case that at times the static mode seems 'embedded' within the dynamic mode, in the sense that it may target any one of the points of time in the sequence of events presented by the dynamic mode. The distinction between a dynamic mode and a static mode of presenting information is shown next to play a role in the patterning of word order data.

\subsection{The Static Mode of Presenting Information and the Distinction between Eventuality Existentials and Predication Clauses}

It is shown next that the static mode of presenting information can assemble numerations with agentive predicates as eventuality existentials. Consider ( 36$)$, where the subject is not discourse-linked and the sentence is interpreted along the lines 'There is information coming from Mary that .... Example (36) is a static mode description, where the speaker zooms in on current time and reports an anterior event with current relevance.

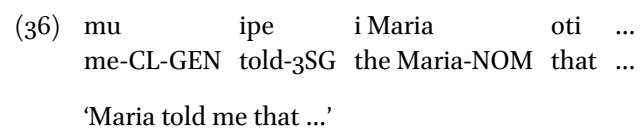

The interpretation of verb-initial sentences with agentive predicates, in fact all types of predicates, in the static mode has strong affinities, with two, allegedly independent, structures that have been discussed with respect to a number of languages, i.e. the 'hot news' reading of the perfect and historical present/ 
dramatic present. Next, I will look at these structures. The 'hot news' reading is the description for one of the readings of the perfect in English (cf. (37a)). Interestingly, that reading is expressed in Standard Greek as a verb-initial order with a past tense verb (cf. $(37 \mathrm{~b})$ ); the perfect is blocked from this use. The subject in $(37 \mathrm{a}-\mathrm{b})$ is not discourse-linked.

(37) a. The Portuguese FOREIGN minister has handed in his resignation.

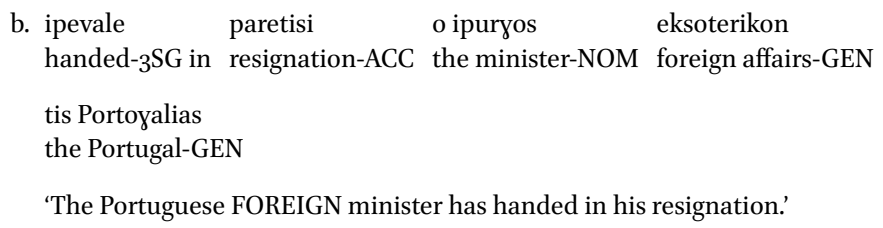

Arguably, the so-called 'hot news' reading associated with the English perfect and the same interpretation associated with the Greek verb-initial order hold for all predicate types, and have the same account, i.e. eventuality existentials in the static mode.

Concerning the second structure, historical present is used for vivid presentations of past events (cf. (38a), taken from a joke), while dramatic present is used when the speaker reports events in real time, as in the broadcasting of sports events (cf. $(38 b))$. Both (38a) and (38b) involve agentive predicates.

(38) a. SIKONI lipon to heri tu o toksotis

RAISE-3SG well the hand-ACC his the archer-NOM

'Well the archer raises his hand ...'

b. perni tibala o Rivaldo sutari ke ...

'Rivaldo gets the ball, he shoots and ....'

It is proposed that examples $(38 \mathrm{a}-\mathrm{b})$ involve the static mode of presenting information. But those examples certainly involve sequences of events. There appears to be a contradiction here, if, as claimed, the static mode of presenting information is not used for sequences of events, but simply for describing a state-of-affairs. What, I think, is going on with the historical/dramatic present is that sequences of events are presented in an unorthodox way, i.e. by using the static mode. Consecutive shots of static-mode presentations give the impression of a sequence of events, just like in films it is fast-changing consecutive shots that give the impression of event flow. This different way of 'doing' a sequence of events is responsible for the 'vivid presentation of an event' feeling that is associated with the historical/dramatic present, i.e. the impression that we see action happening live. 
Given that in the static mode eventuality existentials can be assembled from all types of predicates, earlier claim (20) holds for the dynamic mode alone, and needs to be revised as in $\left(20^{\prime}\right)$.

$\left(20^{\prime}\right)$ In the dynamic mode:

a. Eventuality existentials portray transformations.

b. Predication clauses portray actions.

The fact that in the static mode eventuality existentials are assembled from all types of predicates does not entail that in the static mode eventuality existentials portray both transformations and actions. Similarly, in the static mode predication clauses are assembled from all types of predicates. For instance, the meaning 'be behind sb/sth' for akolu $\vartheta$, which is not possible for the subjectinitial order in the dynamic mode (cf. $(2 \mathrm{~b})$ ), becomes possible in the static mode. Again, the fact that in the static mode predication clauses are assembled from all types of predicates does not entail that in the static mode predication clauses portray both transformations and actions. The transformation versus action distinction is only valid if there is a sequence of events. It is not valid for either eventuality existentials or predication clauses in the static mode. In static mode predication clauses the property attributed to an entity could refer to the state resulting from a transformation or from having done a particular action/ having taken a particular option, and this property could range from a stage-level to an individual-level property (cf. (21)), depending on which time interval is described in the static mode. The essential question is why the static mode has this effect. A possible answer could be along the following lines. Zooming in on a particular time interval imposes the restriction that an anterior event can be reported neither with a definite event time nor in relation to other events in a sequence of events, but is only placed in time in relation to the time interval the speaker chooses to zoom in on, and is, therefore, characterized as anterior with respect to that time interval. What zooming in on a particular time interval, and the concomitant 'dependent' temporal reference of reported events, appears to do is 'trivialize' the distinction between a transformation and an action, namely the distinction between an event happening without obvious external causation and a caused event that would have to be an individual's action. If there is no story to be told (i.e. a sequence of events), then whatever is told is put either in a list of events (and this is eventuality existentials in the static mode) or is information filed under individuals (and this is predication clauses in the static mode). In both the dynamic and the static mode of presenting information a clause is marked for what it expresses, namely an eventuality existential or a predication clause. In the dynamic mode the content of an eventuality existential is perceived as a transformation, while the content of a predication clause is perceived as an 
action. This has to do with the fact that the events form part of a sequence of events. In the static mode, on the other hand, the eventuality existential versus predication distinction is not 'overlaid' with the additional semantic layer of the transformation versus action distinction, because that semantic layer only makes sense in a sequence of events. It appears that definite event time or relative time with respect to other events in a sequence of events is required for an event to be perceived as a transformation or as an action. We also need to identify what determines in the static mode whether a numeration is assembled as an eventuality existential or a predication clause. A possible hypothesis is that what plays a role is a background/ foreground distinction with respect to a particular scene. The entities included in the scene appear in predication clauses; everything else appears in eventuality existentials. At this point I would like to go back to earlier examples (5b), (6b-c), (23), and $(24 \mathrm{~b})$. Examples $(5 \mathrm{~b})$ and $(6 \mathrm{~b}-\mathrm{c})$, and the meanings 'be the driver' for oði in $(5 \mathrm{~b})$ and 'some singer's $\mathrm{CD}$ is playing or there is a live performance by that singer' for tra $u$ 孔o in (6b), are only compatible with the static mode of presenting information. And CLLD (cf. $(23 b)$ and $(24 b)$ ) is only compatible with the static mode.

As a more general comment, a reviewer observes that it is standardly assumed that VSO and VOS structures are well-formed in Greek. If so, an example like in (39a) below (the reviewer's example), with no contrastively focused constituent, seems to refute the claim that V-initial orders are orders of unaccusative predicates, embedded structures or structures where historical present is used. The reviewer points out that the paper should discuss the differences in interpretation that warrant the claim that VSO in (39a) and SVO in (39b) are derived from different numerations.

(39) a. efaye o Nikos to yliko
ate-3SG the Nikos-NOM the cake-ACC
$\begin{aligned} \text { b. o Nikos efaye to yliko } \\ \text { the Nikos-NOM ate-3SG the cake-ACC }\end{aligned}$

My first point is that, because ungrammaticality in the examples discussed in this paper does not have to do with some morphological violation, it is felt to be milder than other violations. In order to judge a particular word order in Greek as grammatical/acceptable or ungrammatical/unacceptable, what we need to establish first is with respect to which mode of presenting information we check the grammaticality/acceptability of the sentence. This syntactic notion 'replaces' in my system the notion of context. For my intuitions, example (39a) cannot be uttered in the dynamic mode, i.e. in a sequence of events narration. The test for all native speakers is to put (39a) in a sequence of events and say if they like it. In (39c) below we have a sequence of events, i.e. going back home, 
Nikos eating the cake, going to sleep. What is in parentheses is an interpolated part in the static mode. The question is whether native speakers like or use the verb-initial order for the second event. I happen not to. If, in (39c), one assembled the numeration $\{$ efaye, $\gamma$ liko, to, Nikos, $o\}$ as a verb-initial order, this would certainly not lead to a major ungrammaticality, but, still, I do not think that most native speakers would prefer this word order.

(39) c. Yirisame spiti. (Sto trapezi ipirhe mono ena komati yliko. Imastan poli kurazmeni. Đen iha mayirepsi.) Efaye o Nikos to rliko ke piyame ya ipno.

'We went home. (There was only a piece of cake on the table. We were very tired. I hadn't cooked anything.) Nikos ate the cake and we went to sleep.'

The only possibility in the dynamic mode would be (39b). And for me, it is this sentence that would be used in a text like (39c). (39a), on the other hand, is a word order that could be used in the static mode. Namely, it could be the complement of a sentential operator. If texts can be found where sentences like (39a) are part of a sequence of events, then the proposed theory will need to be revised.

\section{The [Eventuality Existential] vs. [Predication] Distinction and Universal Grammar}

For an analysis in terms of clause types to go through for the verb-initial/ subject-initial distinction in Greek, the proposed clause type distinction between eventuality existentials and predication clauses must be part of Universal Grammar, irrespective of the syntactic manifestation of the two clause types in a particular language. This section precisely examines whether the proposed distinction is part of Universal Grammar. We will have an argument for this claim, if it turns out that this distinction is overtly marked in a large number of, if not all, languages. The syntactic manifestations of this distinction in English are briefly discussed.

As a semantic distinction, the distinction between eventuality existentials and predication clauses, where all sentences are marked as having one or the other value, seems general enough in its scope to be part of Universal Grammar. Sasse (1987) has in fact shown that the thetic/categorical distinction is syntactically manifested in a considerable number of languages. More specifically, it is claimed that in English thetic sentences include subject-accented sentences, weather expressions and there-sentences. By subject-accented sentences what is meant is sentences which have an accent (: high pitch) on the subject only; sentences which have an accent on both the subject and the verb are excluded. It is shown that in German, as well, thetic sentences are manifested as subjectaccented sentences and impersonal sentences. In a large number of languages, 
which include Italian, Spanish, Greek, Albanian, Hungarian, Slavic languages, Arabic dialects and Chinese, among others, thetic sentences are marked, in Sasse's (1987) terms, with subject inversion. Apart from intonation and word order, a third strategy languages use to mark thetic sentences is the so-called split structures, i.e. structures with the subject coming first (optionally preceded by an existential marker) and the rest of the sentence following in the form of a relative clause. Languages with split structures include French, which is extensively discussed, Celtic languages and Egyptian Arabic, among others. Incorporation and verb nominalization are shown to be two more structures used by languages to mark thetic sentences. The manifestation of thetic sentences in a language is determined to some extent by clause-structure properties of that language. In particular, English, which does not allow for word order variation, like Greek does, would have to have a way of marking thetic judgments (: eventuality existentials in this paper's terms) other than the verbinitial order. It is finally argued that the thetic/categorical distinction is not a matter of information structure, but can be accounted for in terms of expectation. In Sasse's (1987:568-569) description, "the thetic type of statement is used whenever the speaker assumes that the hearer expects unitary information to be given about the whole situation in question, and the categorical type of expression is used whenever he assumes that the hearer expects information units about the constituent parts of the situation to be built up successively". I do not share Sasse's account for the distinction, and have presented an alternative account.

As claimed by Sasse (1987), English, a fixed word order language, has two syntactic means for marking thetic judgments (: eventuality existentials in this paper's terms), i.e. sentences with preverbal stressed subjects (cf. (40)) and there-sentences (cf. (41)).

(40) a. Then the LETTER came from my sister.

b. DETAILS arrived of the Italian property.

c. A MAN was killed, and several others were injured.

d. My WATERS broke.

e. JOHN rang.

(41) Lumsden (1988)

a. There appeared an angry crowd.

b. There dwelt in that house an old man.

c. There ran into the room a small boy.

d. There emerged some/several new facts at the meeting.

In terms of the discussion in the previous section, example (40a) is a clear case of the dynamic mode, given the marker then, which precisely indicates that we have a sequence of events. Examples (4ob-e), as they are, sit more comfortably with the static mode. They can, however, be inserted in the dynamic mode, if, 
for instance (4ob, d, e) started with a modifier like then, as (40a) does, or at that point. Example (40c) would need to start with the modifier in that incident. As for (41), example (41b) is in the static mode, while examples (41a, c) are in the dynamic mode and (41d) could be in either. All the predicates in examples (40) and (41) are unaccusative predicates. According to claim (15) of Section 4.2, repeated below, they would be eligible to form eventuality existentials. The predicate ring in (40e) is interpreted as 'get in touch'. The predicate run into in (41c) is a movement verb.

(15) The \pm unaccusative distinction is the basis for the distinction between eventuality existentials and predication clauses.

I would like to add one more manifestation of eventuality existentials in English. Namely, apart from the verbal existential sentences in (41), there are the periphrastic existential sentences in (42). In fact, we could refer to both verbal existential sentences and periphrastic existential sentences with the term there-existentials. The predicates in (42b-d) are unaccusatives.

(42) Milsark (1974)

a. There is a man swimming.

b. There was a man caught.

c. There is a man drunk.

d. There was a man being interrogated.

So in the case of periphrastic existential sentences, as well, we have to do mainly with unaccusative predicates, that is to the exception of swim in (42a).

I will next look at (42a) and arguably similar cases (cf. (43a-b) and earlier (37a), repeated below). They are all interpreted as eventuality existentials, and this is syntactically marked with a stressed subject or a vP-internal subject in a there-existential. Because it could be thought that $(43 \mathrm{~b})$ involves focus on the subject, I describe here the context in which $(43 \mathrm{~b})$ was actually used. There was a business dinner at a restaurant, Mary was one of the dinner guests, Mary's husband would join them later on for coffee, they were still eating when he arrived, they asked him why he hadn't joined them earlier and invited him to have a bite. He politely refused uttering (43b).

(43) a. A BOY has danced. (Zubizarreta 1998)

b. MARY cooked for me.

(37) a. The Portuguese FOREIGN minister has handed in his resignation.

The similarity among examples (42a), (43a-b) and (37a) is that they can only be uttered in the static mode of presenting information, in the sense that they cannot form part of a flow of events. For instance with respect to (42a), the speaker zooms in on a particular time interval and reports that there is a 
person swimming. We should also consider earlier examples (4ob-e) and (41d), which can optionally be used in the static mode. Examples (43a) and (37a) use the perfect, which according to Agouraki (2011) is a marker of the static mode for anterior events. The proposal in (15) predicts that the predicates arrive of (40b), be killed of (40c), break of (4od), emerge of (41d), be caught of (42b), and be interrogated of (42d) can yield eventuality existentials in their capacity as unaccusative predicates, irrespective of whether the mode of presenting information is dynamic or static. What examples (42a), (43a), (43b) and (37a) additionally show is that in English, as well, just like in Greek, the static mode yields eventuality existentials for all predicate types. And this is shown because swim of (42a), dance of (43a), cook of (43b) and hand in one's resignation of (37a) are agentive/intentional predicates and could not possibly be assembled as eventuality existentials in the dynamic mode.

To sum up so far, in English eventuality existentials are manifested as thereexistentials or as subject-initial clauses with stress on the subject, as opposed to predication clauses, which are also subject-initial but with no stress on the subject. More generally, whatever the syntactic manifestations of the proposed semantic clause type distinction in a particular language, the prediction is that the manifestations for the two clause types should be in complementary distribution in the dynamic mode, and that this complementary distribution should be determined by predicate type. As for the static mode, the claim is that the distribution of the two clause types does not solely depend on predicate type.

\section{The Syntactic Derivation for the Two Clause Types}

The final aim is to consider the syntactic status of the distinction between eventuality existentials and predication clauses. The complementary distribution of eventuality existentials and predication clauses, the syntactic account of their distribution pattern in terms of syntactic types of predicates, the syntactic realization of this distinction in a variety of languages, and the relationship between clause structure properties and the manifestation(s) of this distinction in a particular language constitute four pieces of evidence for the syntactic status of the distinction. It is argued that the same four pieces of evidence support a particular type of analysis for the distinction between eventuality existentials and predication clauses. At the same time, the syntactic analysis/derivation should be compatible with the semantic interpretation and some proposal for the semantic derivation of the two clause types. Additional facts that need to be taken into account include the following: (a) There is no difference in the uninterpretable features of the verb in verb-initial and subject-initial clauses. This implies that verb-initial clauses cannot possibly involve verb movement 
to a higher functional head in order to check some uninterpretable feature on the verb. And (b) because subject-initial clauses in Greek are semantically equivalent to subject-initial clauses in English, i.e. they are both interpreted as predication clauses, it is not possible to offer a Topicalization-type analysis for subject-initial clauses in Greek. Arguably, the general claim that there is a difference in the interpretation of the subject in the subject-initial word order in Greek (i.e. a Topicalization-type analysis) is an inadequate description of the intuition that in subject-initial clauses the relationship between the predicate and the subject differs from the relationship between the predicate and the subject in verb-initial clauses. What is perceived as a distinct interpretation of the subject in the subject-initial word order has to do not with the interpretation of the subject as such, but with how the subject merges with the predicate.

In line with the semantic clause type proposal for the distinction between eventuality existentials and predication clauses, defended in Section 4.2, it is claimed next that the distinction between eventuality existentials and predication clauses is encoded in syntax as a low distinction between two clause types, low in the sense that it is marked lower than the functional head that marks the distinction between matrix and embedded sentences. If we only had to account for the Standard Greek and the English data, we could say that this is an inflectional level clause type distinction..$^{10}$ Because the same distinction is manifested in dialects or languages where the verb is in C (cf. Cypriot Greek or German), we will need to say that this is an inflection-level or a complementizerlevel distinction.

According to the Principle of Compositionality, semantic interpretation rules pair with syntactic formation rules. This means that this distinction also has to do with how a clause is put together syntactically, and not only semantically. The semantic hypothesis I explored, according to which in predication clauses it is the first-order property denoted by the predicate that saturates the second-order property denoted by the subject DP, is compatible with a syntactic hypothesis according to which in predication clauses the subject merges externally. The specifics of the syntactic proposal for this clause type distinction

\footnotetext{
10) A reviewer observes that if the distinction between eventuality existentials and predication clauses is an IP-level distinction, mediated through I, as argued in the paper, it should have a morphological exponent at least in some languages. This is a prediction of the theory, which I have not checked. What could be taken to constitute morphological evidence from Greek concerns CLLD. The obligatory presence of the clitic in these clauses fits the description of morphological evidence. The clitic in those cases is like an obligatory object agreement marker on the verb.
} 
in Standard Greek, English and Cypriot Greek, i.e. two dialects and two languages with clause structure differences, are summarized in (44)-(49) below.

(44) General dynamic mode settings

a. The clause type distinction between eventuality existentials and predication clauses is marked in syntax.

b. The head that hosts the binary distinction is the head the verb/auxiliary raises to in matrix clauses (i.e. I or $\mathrm{C}$, depending on the dialect/ language).

(45) Dynamic mode settings for Standard Greek

a. When I has the value [predication], it bears two uninterpretable features: one uninterpretable feature specifies the functional projection selected by I, i.e. [uagentivev], and the other uninterpretable feature is [usubjectofpredication].

When I has the value [eventuality existential], it bears two uninterpretable features: one uninterpretable feature specifies the functional projection selected by I, i.e. [uunaccusativev], and the other uninterpretable feature is a requirement for an existential closure operator (over events), i.e. [ $u \exists \mathrm{e}]$, to fill [Spec,IP].

b. In predication clauses the subject DP is externally merged in [Spec,IP], in order to satisfy the [usubjectofpredication] feature on I. The subject in [Spec,IP] is coindexed with an internally merged null nominal operator in [Spec,vP]. The vP that merges with the subject DP in [Spec,IP], through the intermediary of the I-head, is a predicate created from a clause, and is semantically parallel to a relative clause. The null nominal operator is like a relative operator.

c. In eventuality existentials the existential closure operator in [Spec,IP] is silent.

The claim in (45b) that preverbal subjects are externally merged into [Spec,IP] is a different realization, involving, crucially, a different, i.e. semantic, motivation, of the main idea in the standard analysis of preverbal subjects in Greek, i.e. the analysis that preverbal subjects are adjuncts, base-generated above the TP domain; in that case [Spec,vP] was taken to be occupied by a pro (cf. Tsimpli 1990, Alexiadou and Anagnostopoulou 1998, Spyropoulos and PhilippakiWarburton 2001).

As shown in Section 7, in English eventuality existentials are realized as subject-initial sentences with stress on the subject or as there-existentials. The proposal for eventuality existential settings in English appears in (46) below.

(46) Dynamic mode settings for English

a. Same as for Standard Greek (cf. 45(a)).

b. Same as for Standard Greek (cf. $45(\mathrm{~b})$ ).

c. In eventuality existentials the existential closure operator in [Spec,IP] is overtly realized. There are two ways to satisfy this requirement: The expletive there is externally merged into [Spec,IP]. Alternatively, the subject is internally merged into [Spec,IP], in order to check $[u \exists \mathrm{e}]$. The evidence for the motivation of this movement is the fact that the [Spec,IP] subject in eventuality existentials is obligatorily stressed.

The settings for Cypriot Greek, and V2 dialects/ languages in general, differ from the settings for Standard Greek/ English in that the head that hosts the binary distinction is $\mathrm{C}$ (for the claim that in Cypriot Greek the verb is in C see Agouraki 1997, 2001). The settings for Cypriot Greek appear in (47) below. 
(47) Dynamic mode settings for Cypriot Greek

a. When $\mathrm{C}$ has the value [predication], it bears two uninterpretable features: one uninterpretable feature specifies the functional projection selected by $\mathrm{C}$, i.e. $[u \mathrm{I}]$, and the other uninterpretable feature is [usubjectofpredication]. I bears the uninterpretable feature [uagentivev].

When $\mathrm{C}$ has the value [eventuality existential], it bears two uninterpretable features: one uninterpretable feature specifies the functional projection selected by $\mathrm{C}$, i.e. $[u \mathrm{I}]$, and the other uninterpretable feature is a requirement for an existential closure operator (over events), i.e. $[u \exists \mathrm{e}]$. I, to fill in [Spec,CP], bears the uninterpretable feature [uunaccusativev].

b. In predication clauses the subject DP is externally merged in [Spec,CP], in order to satisfy the [usubjectofpredication] feature on $\mathrm{C}$. The subject in [Spec,CP] is coindexed with an internally merged null nominal operator in [Spec,vP]. The vP that merges with the subject DP in [Spec,CP], through the intermediary of the C-head/I-head, is a predicate created from a clause, and is semantically parallel to a relative clause. The null nominal operator is like a relative operator.

c. In eventuality existentials the existential closure operator in $[\mathrm{Spec}, \mathrm{CP}]$ is silent.

Concerning the settings for a $\mathrm{V}_{2}$ language like German, where, contrary to $\mathrm{Cy}$ priot Greek, the subjects of eventuality existentials cannot appear in their thematic position (to the exception of embedded clauses), it would be interesting to see whether [Spec,CP] subjects of eventuality clauses in German are obligatorily stressed, just like [Spec,IP] subjects of eventuality clauses are obligatorily stressed in English. The matrix/embedded distinction in German with respect to the position of the subject is also interesting to look at, in relation to the discussion on word order and sentential operators in Section 5 .

The syntactic proposal in (44)-(47), and in particular the uninterpretable features on I/C most adequately describe the fact that in the dynamic mode it is predicate type that determines clause type. In the static mode, on the other hand, it is possible for all predicate types to yield either clause type, with the ensuing meaning difference. The static mode settings that differ from the corresponding dynamic mode settings appear in (48) and (49) below, for Standard Greek and Cypriot Greek, respectively.

(48) Static mode settings for Standard Greek

a. When I has the value [predication], it bears two uninterpretable features, i.e. [uv] and [usubjectofpredication].

b. When I has the value [eventuality existential], it bears two uninterpretable features, i.e. $[u \mathrm{v}]$ and $[u \exists \mathrm{e}]$.

(49) Static mode settings for Cypriot Greek

a. When $\mathrm{C}$ has the value [predication], it bears two uninterpretable features, i.e. [uI] and [usubjectofpredication].

b. When $\mathrm{C}$ has the value [eventuality existential], it bears two uninterpretable features, i.e. $[u \mathrm{I}]$ and $[u \exists \mathrm{e}]$. 


\section{Conclusions}

The paper discussed the distinction between verb-initial and subject-initial clauses in Greek. It was claimed that this word order distinction is the manifestation of a clause type distinction between eventuality existentials and predication clauses. The distinction is accounted for in terms of two factors, i.e. the syntactic type of the predicate and the syntactic notion of mode of presenting information. The notion of mode of presenting information, crucially, puts the text into the discussion of syntactic phenomena like word order. It remains to be examined how the theory fares with data from different languages. At the same time, a larger dataset from Greek will also need to be examined.

\section{References}

Agouraki, Yoryia. 1992. Clitic-Left-Dislocation and Clitic Doubling: A Unification. UCL Working Papers in Linguistics 4: 45-70.

Agouraki, Yoryia. 1993. Spec-Head Licensing: The Scope of the Theory. Ph.D. Dissertation, University College London.

Agouraki, Yoryia. 1997. On the Enclisis/Proclisis Alternation. In Gaberell Drachman, Angeliki Malikouti-Drachman, Jannis Fykias and Celia Klidi (eds.), Proceedings of the Second International Conference on Greek Linguistics. Volume 2, 393-404. Salzburg: University of Salzburg.

Agouraki, Yoryia. 2001. The Position of Clitics in Cypriot Greek. In Angela Ralli, Brian Joseph and Mark Janse (eds.), Proceedings of the First International Conference of Modern Greek Dialects and Linguistic Theory, 1-18. Patras: University of Patras.

Agouraki, Yoryia. 2009. Clefts in Cypriot Greek. In Stavroula Tsiplakou, Marilena Karyolemou and Pavlos Pavlou (eds.), Language Variation-European Perspectives II, 13-26. Amsterdam: John Benjamins.

Agouraki, Yoryia. 2010a. It-clefts and stressed operators in the preverbal field of Cypriot Greek. In Kleanthes K. Grohmann and Ianthi-Maria Tsimpli (eds.), Exploring the Left Periphery. Lingua 120: 527-554.

Agouraki, Yoryia. 2010b. Aspects of (Greek) Information Structure: Sentences with topics versus verb-initial sentences. Talk (27/9/2010), University of Cyprus.

Agouraki, Yoryia. 2011. The 'Category' of the Perfect and Modes of Presenting Information. Unpublished manuscript, University of Cyprus.

Alexiadou, Artemis and Elena Anagnostopoulou. 1998. Parametrizing Agr: word Order, V-movement and EPP-checking. Natural Language and Linguistic Theory 18: 491-539.

Chung, Sandra and William A. Ladusaw. 2004. Restriction and Saturation. Cambridge, MA: MIT Press.

Divani, Lena. 2010. A Hungry Mouth. Athens: Kastaniotis Editions S.A.

Georgiafentis, Michael. 2004. Focus and Word Order Variation in Greek. Ph.D. Dissertation, University of Reading.

Jenkins, Lyle. 1975. The English Existential. Tubingen: Max Niemeyer Verlag.

Jullien, François. 1996. A Treatise on Efficacy: Between Western and Chinese Thinking. Hawaii: University of Hawaii Press.

Jullien, François. 2012. Egomio tis Apraksias (In Praise of Inaction). Heraklion: Crete University Press. 
Karystiani, Ioanna. 2006. Swell. Athens: Kastaniotis Editions S.A.

Kechagias, Axiotis. 2011. Regulating Word Order in Modern Greek: Verb Initial and Non-Verb Initial Orders \& the Conceptual-Intentional Interface. Ph.D. Dissertation, University College London.

Kuroda, Sige-Yuki. 1972. The categorical and the thetic judgement. Foundations of Language 9: 153-185.

Kuroda, Sige-Yuki. 1992. Japanese Syntax and Semantics: Collected Papers. Dordrecht: Kluwer Academic Publishers.

Lumsden, Michael. 1988. Existential Sentences: Their Structure and Meaning. London: Routledge.

Milsark, Gary. 1974. Existential Sentences in English. Ph.D. Dissertation, MIT.

Pesetsky, David. 1987. Wh-in-Situ: Movement and Unselective Binding. In Eric Reuland and Alice ter Meulen (eds.), The Representation of (in)Definiteness. Cambridge, MA: MIT Press.

Philippaki-Warburton, Irene. 1982. I simasia tis siras Rima-Ipokimeno-Adikimeno sta Nea Ellinika (The interpretation of the word order Verb-Subject-Object in Modern Greek). Studies in Greek Linguistics 3: 135-158.

Philippaki-Warburton, Irene. 1985. Word order in Modern Greek. Transactions of the Philological Society, 113-143.

Philippaki-Warburton, Irene. 1989. 'Subject' in English and Greek. Proceedings of the 3rd Symposium on the Description and/or Comparison of English and Greek, 11-32. Thessaloniki: Aristotle University, School of English.

Philippaki-Warburton, Irene. 2001. Glosoloyiki Өeoria ke sindaksi tis Ellinikis: i pikilia sti sira ton oron ke i erminia tis (Linguistic theory and Greek syntax: word order variety and its interpretation). Proceedings of the 4th International Conference on Greek Linguistics, 217-231. Thessaloniki: University Studio Press.

Sasse, Hans-Jürgen. 1987. The thetic/categorical distinction revisited. Linguistics 25: 511-580.

Spyropoulos, Vassilios and Irene Philippaki-Warburton. 2001. 'Subject' and EPP in Greek: the discontinuous subject hypothesis. Journal of Greek Linguistics 2: 149-186.

Tsimpli, Ianthi-Maria. 1990. The Clause Structure and Word Order in Modern Greek. UCL Working Papers in Linguistics 2: 226-255.

Zubizarreta, Maria Luisa. 1998. Prosody, Focus, and Word Order. Cambridge, MA: MIT Press. 